Case report

\title{
Doxycycline induced generalized bullous fixed drug eruption - A case report
}

\author{
Selvaraj Nitya ${ }^{\mathrm{a}, *}$, Kameswari Deepa ${ }^{\mathrm{a}}$, Adhimoolam Mangaiarkkarasi ${ }^{\mathrm{a}}$, \\ Kaliaperumal Karthikeyan ${ }^{\mathrm{b}}$ \\ a Department of Pharmacology, Sri Manakula Vinayagar Medical College and Hospital, Puducherry 605107, India \\ ${ }^{\mathrm{b}}$ Department of Dermatology, Sri Manakula Vinayagar Medical College and Hospital, Puducherry 605107, India
}

\section{A R T I C L E I N F O}

Article history:

Received 29 October 2013

Accepted 3 December 2013

Available online 25 December 2013

Keywords:

Bullous eruption

Adverse drug reaction

Doxycycline

\section{A B S T R A C T}

Adverse drug reactions are a major hazard of modern medicine. Fixed drug eruption, which is a cutaneous adverse drug reaction, is commonly seen with antimicrobials and analgesics. Here we report 37year-old female with bullous fixed drug eruptions due to doxycycline administration.

Copyright @ 2013, InPharm Association, Published by Reed Elsevier India Pvt. Ltd. All rights reserved.

\section{Introduction}

Doxycycline is a semisynthetic long acting broad-spectrum antimicrobial drug that inhibits protein synthesis and, thus, bacterial growth by binding to $30 \mathrm{~S}$ ribosome and stops the translational process. It is most commonly used to treat respiratory tract infections such as tonsillitis, pneumonia and bronchitis, intra abdominal infections, rickettsial infections, skin and soft tissue infections, periodontal disease, sexually transmitted diseases and also used in prophylaxis of malaria. Common adverse effects of doxycycline include gastrointestinal upset, hepatotoxicity, renal toxicity, teeth discoloration, hemolytic anemia, phototoxicity and skin rashes. ${ }^{1}$ Exacerbation of cutaneous Lupus Erythematosus had also been reported due to doxycycline therapy. ${ }^{2}$ However, fixed drug eruption due to doxycycline is a rare adverse event. Therefore, here we discuss a case of generalized bullous fixed drug eruption due to doxycycline administration.

\section{Case report}

A 37-year-old female presented to the outpatient Dermatology Department of Sri Manakula Vinayagar Medical College and

\footnotetext{
* Corresponding author. No: 12, Vallalar street, Pethuchettipet, Lawspet, Puducherry 605008, India. Tel.: +919787679839.

E-mail addresses: drnityapharm@gmail.com, cailassame@gmail.com (S. Nitya).
}

Hospital, Puducherry with the history of fluid filled lesions all over the body with pain over the affected areas associated with fever for a period of $24 \mathrm{~h}$. A complete history was taken which revealed that patient had taken one dose of doxycycline prescribed by a local practitioner the previous day following history of accidental fall and sustained injury over her right lower limb. On examination multiple well-defined bullous lesions with intact roof of the blister was observed over the face, chest, abdomen, both arms, forearms, back, thighs and around eyelids (Fig. 1). Few intact flaccid blisters with turbid fluid seen over left arm, left hand, abdomen and thighs. Erythema of the tongue and diffuse superficial fissuring of bilateral soles were present. Palms, genital mucosa and scalp were spared. Pseudo Nikolsky sign was positive.

Patient had been admitted once previously in our hospital with the history of rashes over the trunk which was due to drug intake. However, she didn't have the older prescription and was unaware of the drug that had resulted in the adverse reaction. So we went through her record at Medical Record Department of our hospital and found that the drug reaction was due to doxycycline. All routine blood investigations were within normal limits. Hence doxycycline was diagnosed as a cause of fixed drug eruption and patient was treated with dexamethasone $16 \mathrm{mg}$ intravenously once daily, azithromycin $500 \mathrm{mg}$ once daily orally, antihistamines, saline compresses and other supportive measures. The patient improved and recovered from skin lesions within ten days of admission. The steroid was tapered and patient was discharged with the advice to avoid using doxycycline in future. 


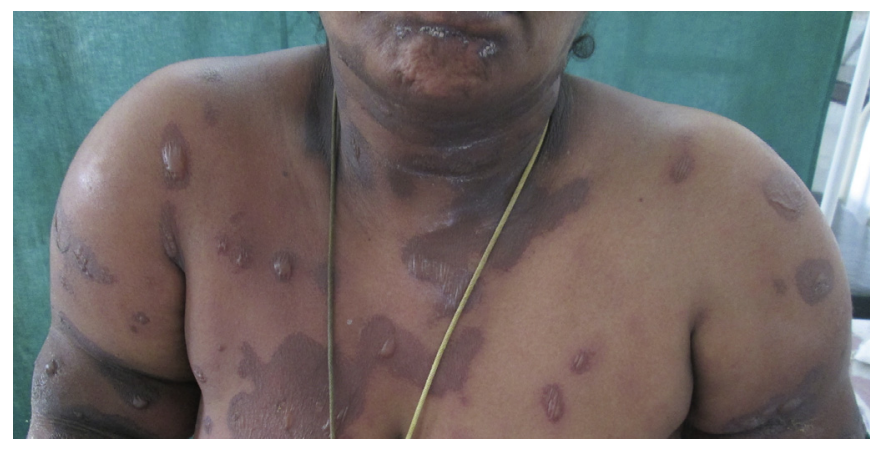

Fig. 1. Multiple well-defined bullous lesions.

\section{Discussion}

Fixed drug eruption (FDE) is the most common cutaneous drug reaction seen in India. Predisposing genetic background probably reflects this adverse drug reaction. ${ }^{3}$ It is characterized by pruritic, well-circumscribed, erythematous patches at the same site with reexposure to an offending drug. Subsequent exposure may increase the number of sites. Usually the lesion will be well-defined round or oval plaque of erythema and edema that may be surmounted by a bulla in the early stages. ${ }^{4}$ Later the lesion subsides upon discontinuation of the drug leaving behind hyperpigmentation. Localized tissue damage is due to intraepidermal clusters of differentiated CD8-positive T cells at the affected site. When the resting T cells are activated, surrounding keratinocytes are killed and release cytokines such as interferon gamma. More T cells and neutrophils are recruited to the FDE site causing tissue damage. ${ }^{3}$

The commonly used drugs causing FDE are antibiotics such as trimethoprim-sulfamethoxazole, penicillin, tetracycline and erythromycin followed by non-steroidal anti-inflammatory drugs (NSAIDS) like diclofenac sodium, aspirin, ibuprofen and naproxen and also some of the antiepileptics. ${ }^{5}$

In this case, patient developed adverse reaction within one day following administration of doxycycline. Naranjo's algorithm (Naranjo, 1981) was used to determine a plausible reaction due to doxycycline. ${ }^{6}$ The following criteria were considered: There were previous conclusion reports on this reaction $(+1)$; the adverse event appeared after doxycycline was administered $(+2)$; Adverse event improved when doxycycline was discontinued (+1); Adverse event reappeared when doxycycline was re-administered (0); alternate causes that could solely have caused the reaction $(+2)$; the reaction reappeared when a placebo was given (0); drug detected in the blood [or other fluids] in a concentration known to be toxic (0); the reaction was more severe when the dose was increased or less severe when the dose was decreased (0); the patient had a similar reaction to the same or similar drugs in any previous exposure $(+1)$; the adverse event confirmed by objective evidence $(+1)$. Based on the total score of 8 , this FDE was categorized as 'probable' reaction to doxycycline administration.

\section{Conclusion}

This case illustrates clinically important and rare cutaneous drug reaction of doxycycline, commonly prescribed antibiotic. Hence, it should be kept in mind that use of doxycycline can result in development of fixed drug eruption and should be prescribed carefully.

\section{Conflicts of interest}

All authors have none to declare.

\section{References}

1. Macdougall C, Chambers HF. Protein synthesis inhibitors and miscellaneous antibacterial agents. In: Brunton LL, Chabner AB, Knollmann CB, eds. Goodman E Gilman's The Pharmacological Basis of Therapeutics. 12th ed. New York, NY: McGraw-Hill; 2011:1521-1526.

2. Miller KK, Chu J, Patel R, Kamino H. Drug-induced subacute cutaneous lupus erythematosus related to doxycycline. Dermatol Online J. 2011;17:3.

3. Pai VV, Bhandari P, Kikkeri NN, Athanikar SB, Sori T. Fixed drug eruption to fluconazole: a case report and review of literature. Indian J Pharmacol. 2012;44: 643-645.

4. Breathnach SM. Drug reactions. In: Burns T, Breathnach S, Cox N, Griffiths C, eds Rook's Textbook of Dermatology. 8th ed. Oxford: Blackwell Science; 2010:28-177.

5. Pasricha JS. Drugs causing fixed eruptions. Br J Dermatol. 1979;100:183-185.

6. Naranjo CA, Busto U, Sellers EM, et al. A method for estimating the probability of adverse drug reactions. Clin Pharmacol Ther. 1981;30:239-245. 